\title{
ReaxFF Simulations of Laser-Induced Graphene (LIG) Formation for Multifunctional Polymer Nanocomposites
}

\author{
Aniruddh Vashisth ${ }^{1,2}$, Matgorzata Kowalik ${ }^{3}$, Joseph C. Gerringer ${ }^{4}$, Chowdhury Ashraf ${ }^{3}$, Adri C.T. van \\ Duin $^{3}$, Micah J. Green ${ }^{2,4, *}$ \\ ${ }^{1}$ Department of Aerospace Engineering, Texas A\&M University, College Station, Texas, 77840, United \\ States \\ ${ }^{2}$ Artie McFerrin Department of Chemical Engineering, Texas A\&M University, College Station, Texas, \\ 77840, United States \\ ${ }^{3}$ Department of Mechanical Engineering, The Pennsylvania State University, University Park, \\ Pennsylvania 16802, United States \\ ${ }^{4}$ Department of Materials Science and Engineering, Texas A\&M University, College Station, \\ Texas 77843, United States \\ * Corresponding Author: micah.green@tamu.edu
}

\section{Supporting Information}

Movie S1: Molecular structure of LIG formed from Kapton at $3000 \mathrm{~K}$ in inert conditions. Carbon atoms are shown as cyan and nitrogen atoms are shown with blue color.

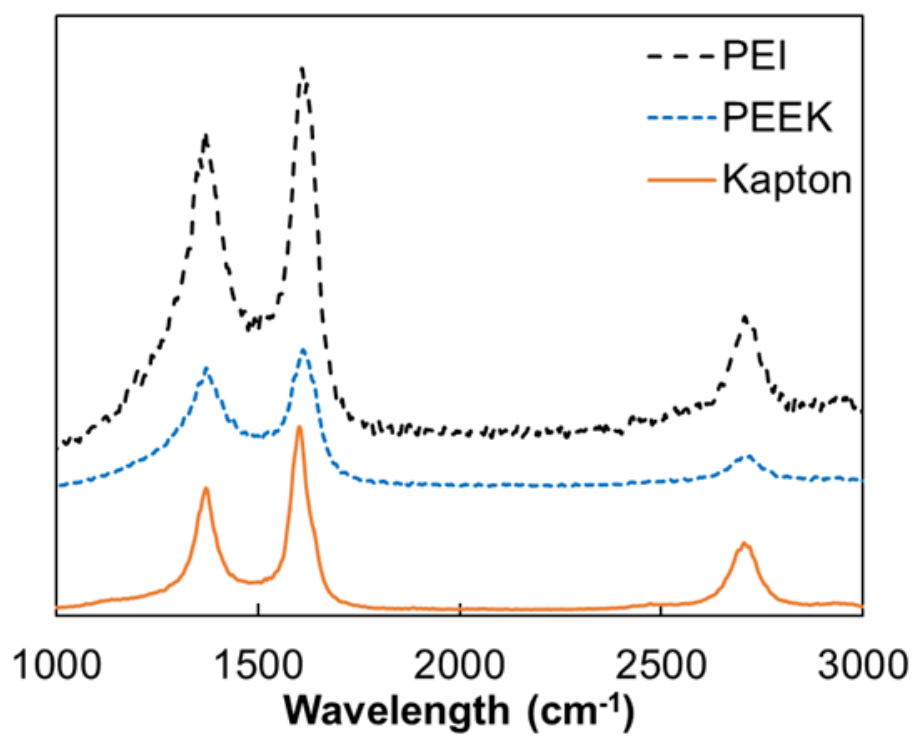

Figure S1: Raman spectrum for LIG films formed from PEI, PEEK and Kapton polymers. 
(a)

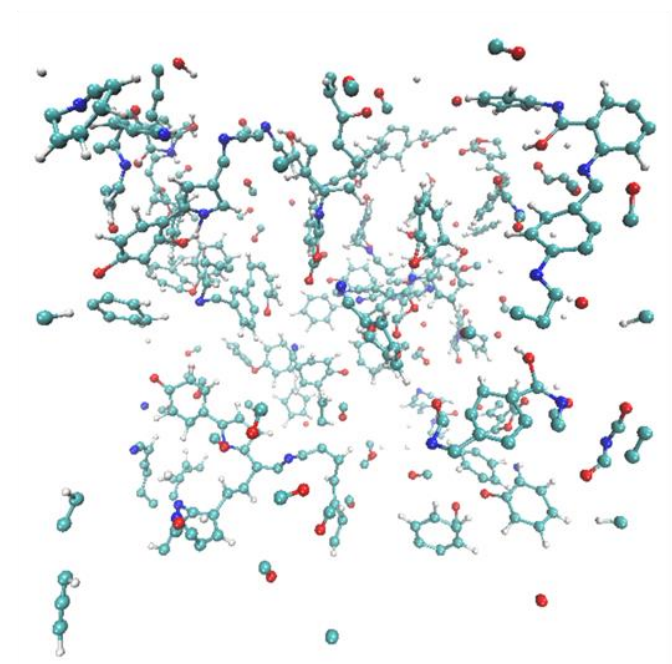

(b)

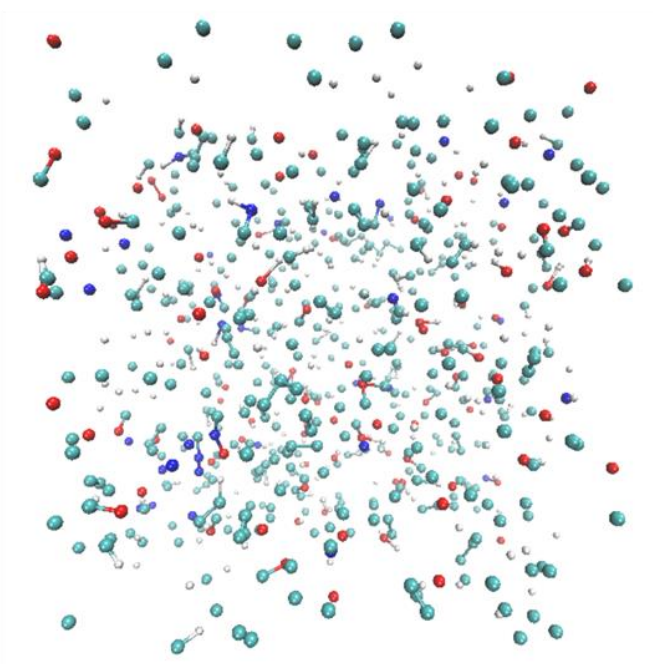

Figure S2: Final structure after $1.25 \mathrm{~ns}$ at elevated temperatures of (a) $2000 \mathrm{~K}$ and (b) $4000 \mathrm{~K}$, starting with Kapton precursor. Simulations carried out at $2000 \mathrm{~K}$ resulted in an amorphous structure, whereas simulations at higher temperatures $(3500 \mathrm{~K}-4000 \mathrm{~K})$ resulted in polymer structure disintegrating into $\mathrm{C}_{\mathrm{x}} \mathrm{H}_{\mathrm{y}} \mathrm{O}_{\mathrm{z}}$ hydrocarbons, $\mathrm{N}_{2}, \mathrm{CO}$ or single atoms. 


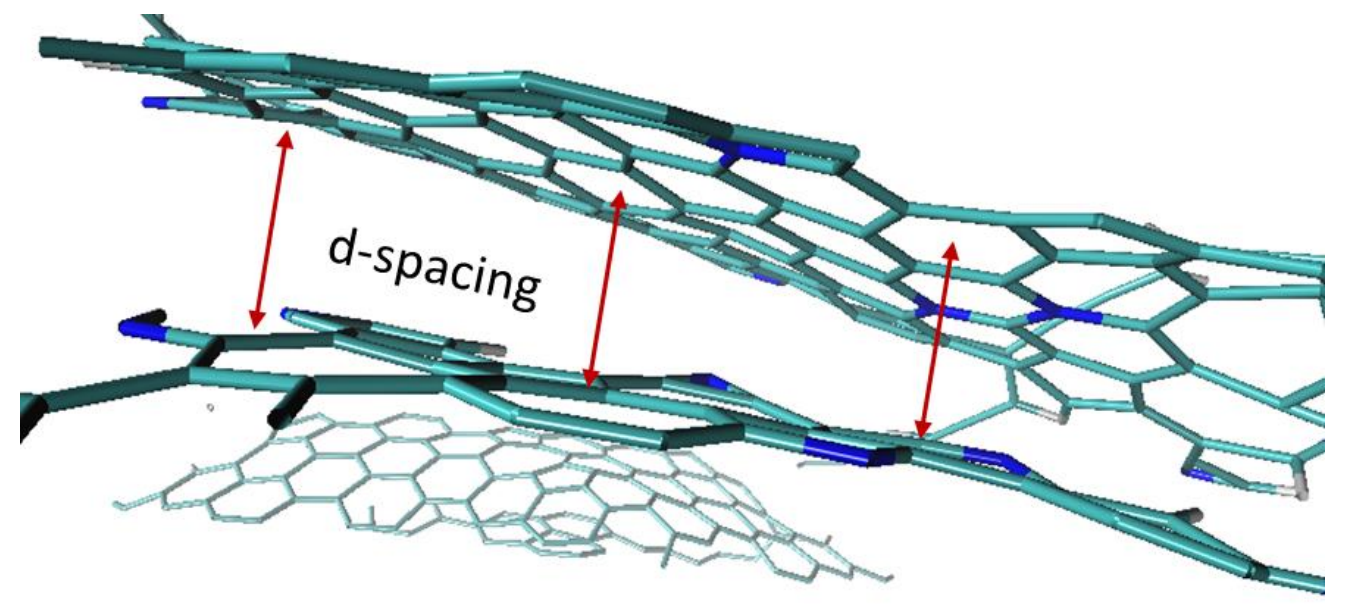

Figure S3: Molecular structure showing the d-spacing between two parallel planes. 
(a)

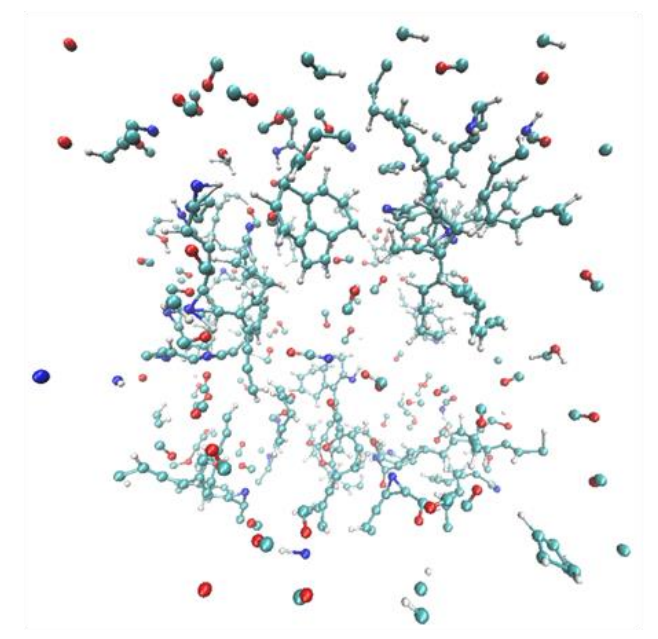

(c)

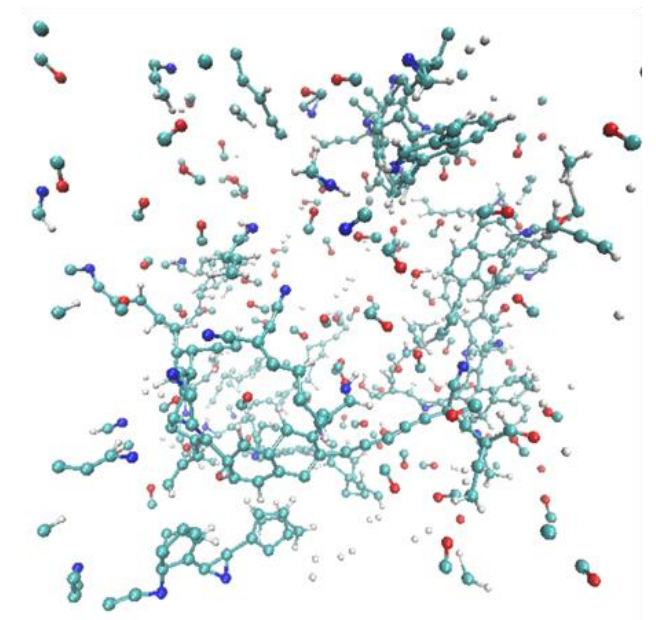

(b)

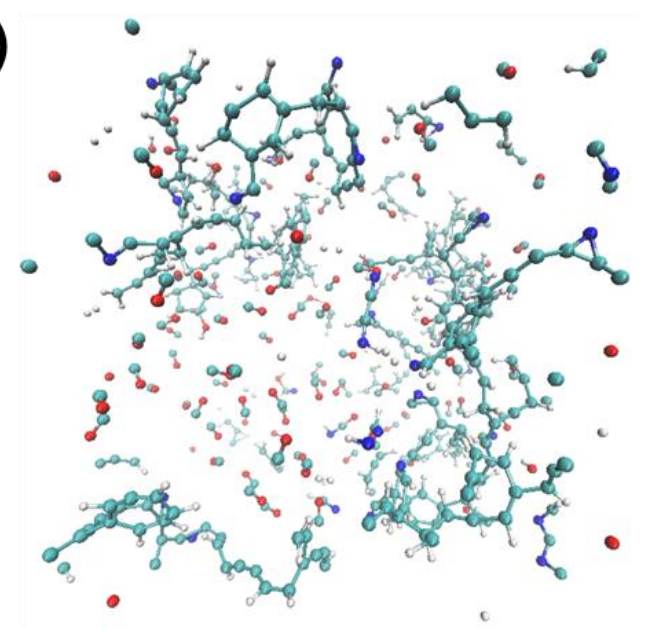

(d)

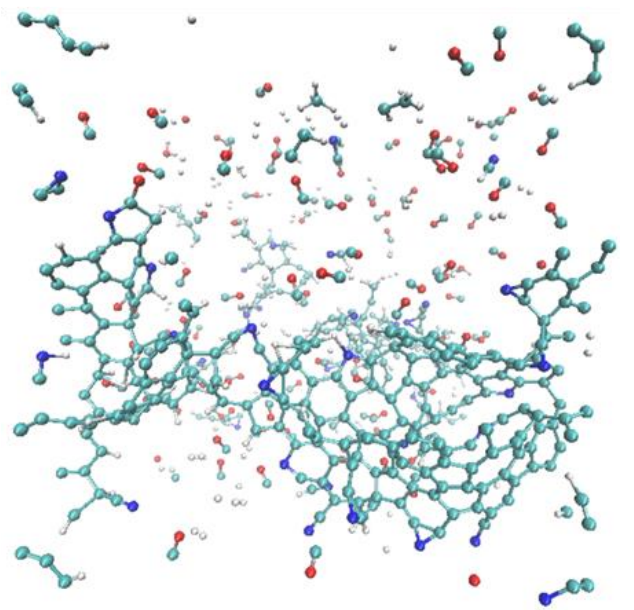

Figure S4: Snapshots at (a) $0.05 \mathrm{~ns}$, (b) $0.1 \mathrm{ns,} \mathrm{(c)} 0.2 \mathrm{~ns}$ and (d) $0.6 \mathrm{~ns}$ to show the formation of amorphous carbon, and subsequent conversion to ordered graphitic structure, for LIG derived from Kapton 


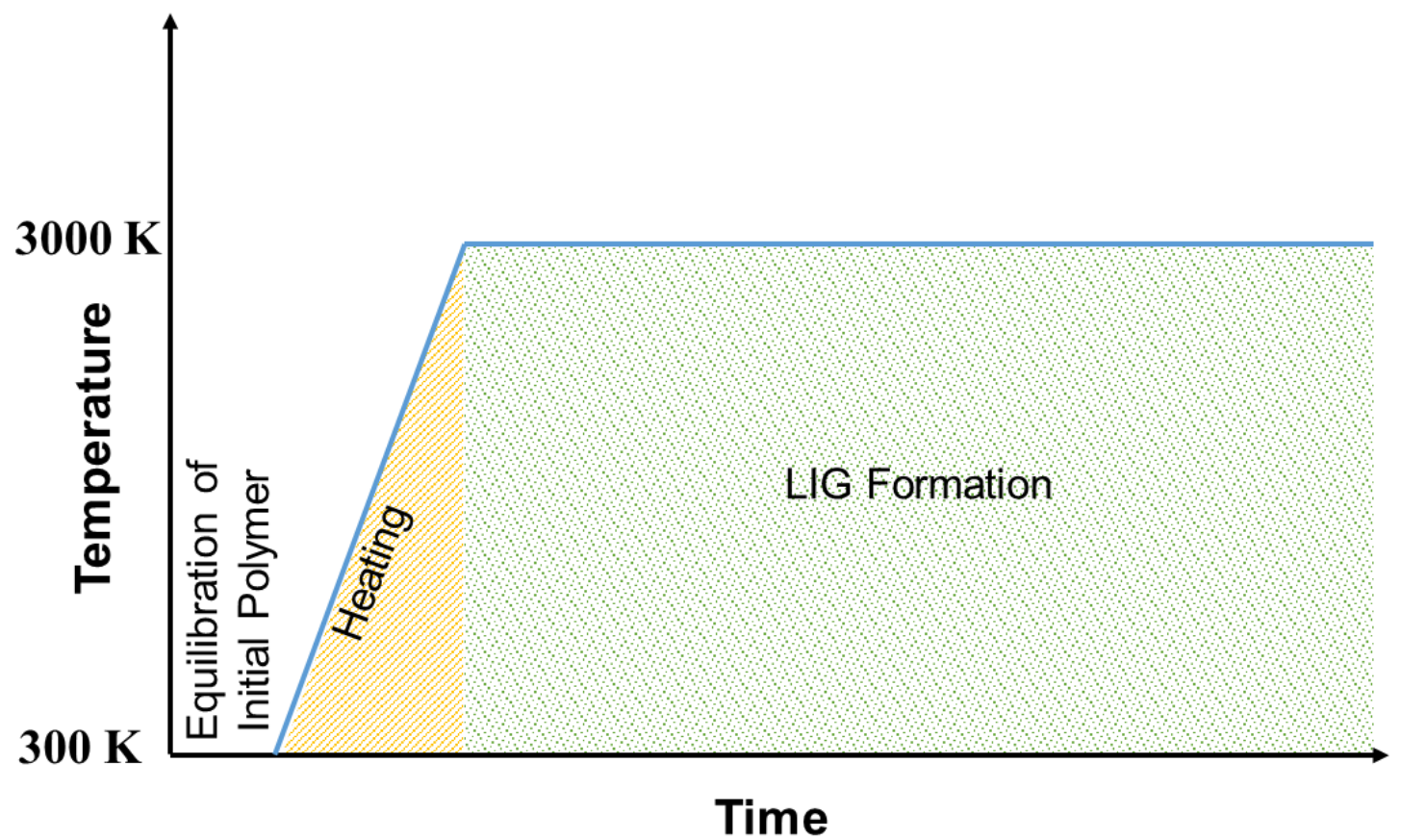

Figure S5: Schematic of the thermal history of all the polymers examined for LIG formation at $3000 \mathrm{~K}$. The system is equilibrated at $300 \mathrm{~K}$ initially and then ramped up to $3000 \mathrm{~K}$ at $200 \mathrm{~K} / \mathrm{ps}$. 


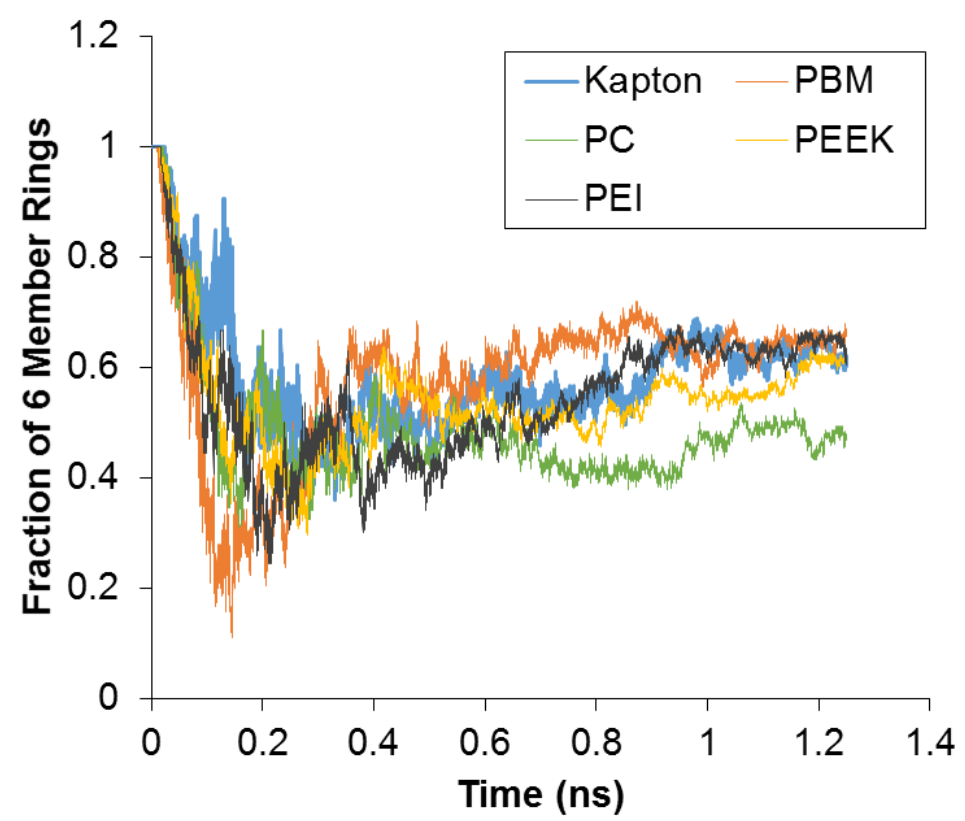

Figure S6: Fraction of 6-member carbon rings in the structure observed from inert condition simulations at $3000 \mathrm{~K}$. Fractions are calculated by dividing the number of 6-member rings at every timestamp by the total number of rings (3- to 8-member carbon rings) at the same instant. 

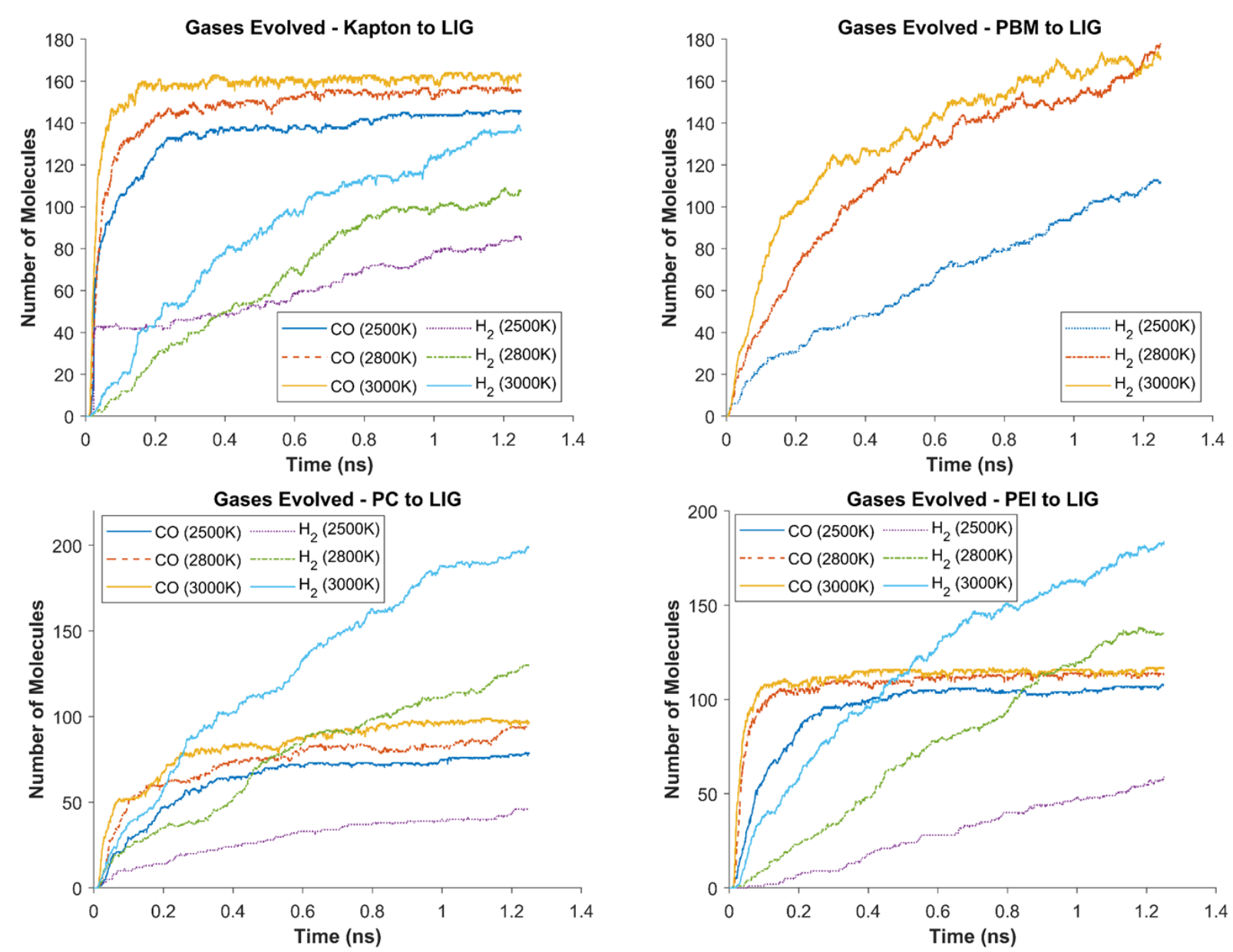

Figure S7: Gases evolved during LIG formation from Kapton, PBM, PC and PEI at different temperatures. 

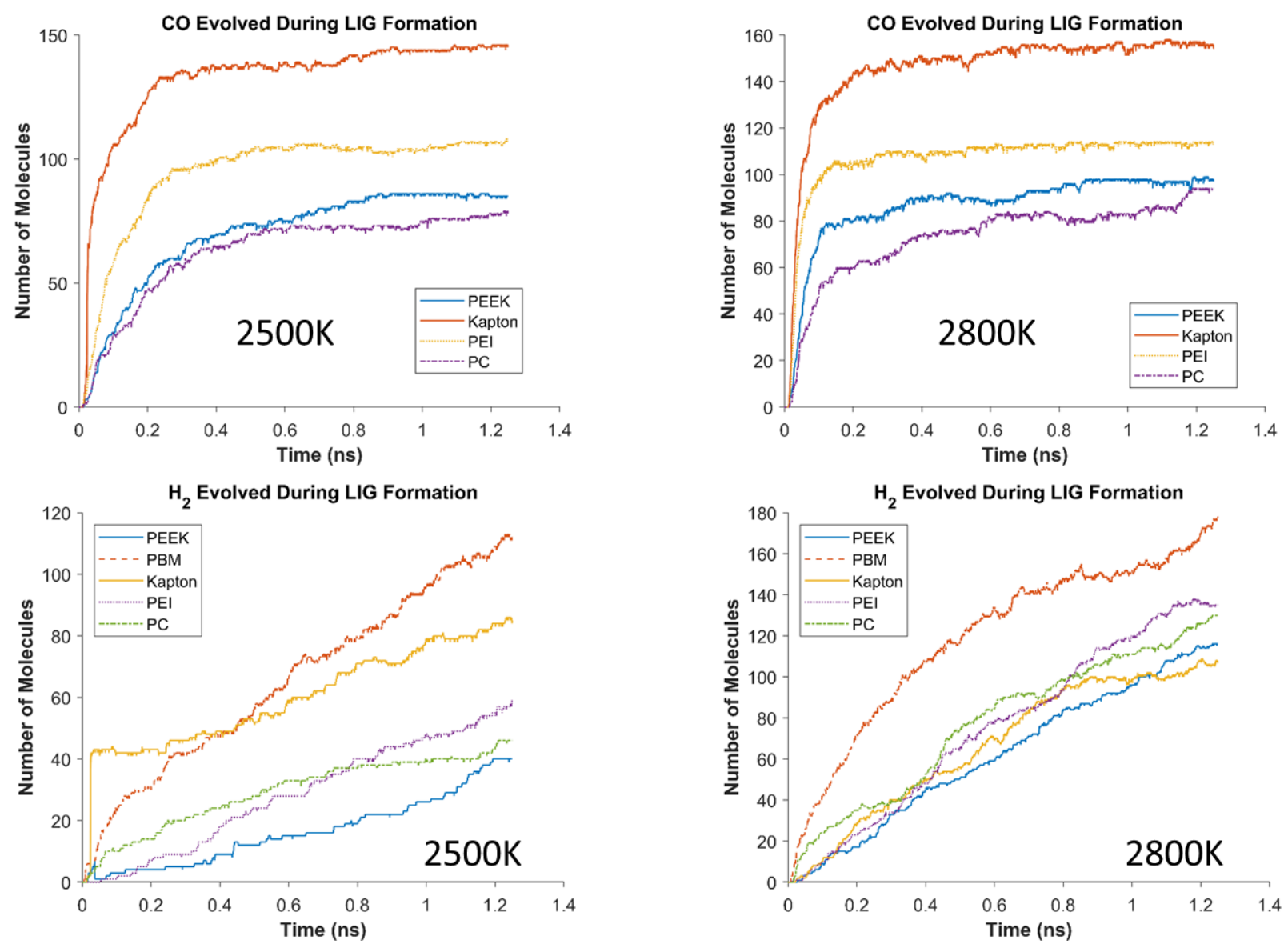

Figure S8: Comparison of different gases evolved during LIG formation from Kapton, PBM, PC and PEI at different temperatures. 

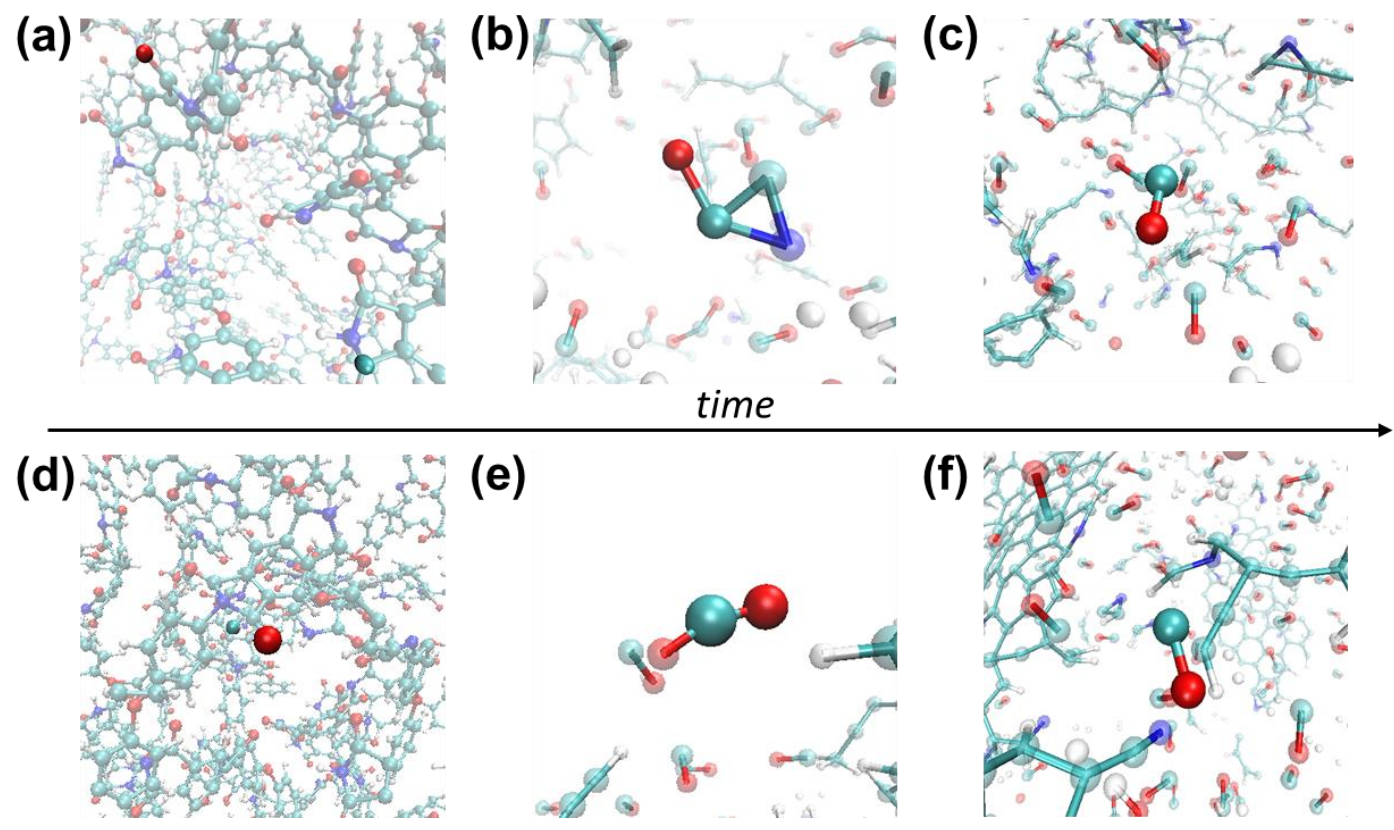

(e)
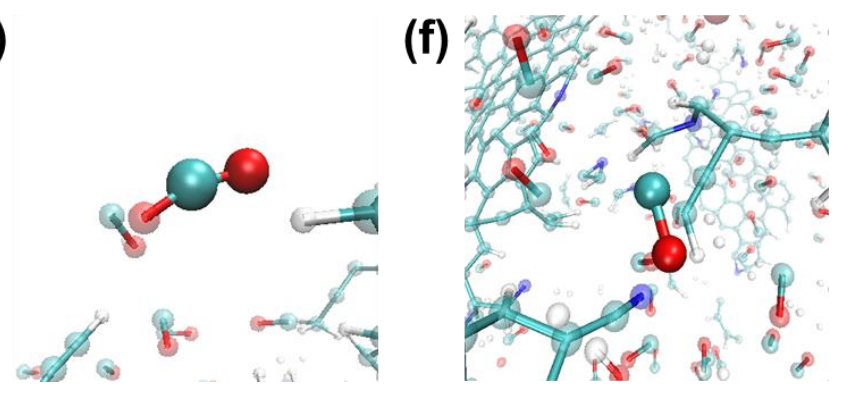

Figure S9: Molecular dynamics snapshots of formation of $\mathrm{CO}$ molecules, where (a-c) shows a hydrocarbon that disintegrates into $\mathrm{CO}$ and $\mathrm{C}_{\mathrm{x}} \mathrm{H}_{\mathrm{y}} \mathrm{N}_{\mathrm{z}}$; (d-f) reveals a $\mathrm{CO}_{2}$ molecule transforming into a $\mathrm{CO}$ molecule during LIG formation from Kapton polymer. 
Table S1: System specifications for different monomers used for LIG formation.

\begin{tabular}{|c|c|c|c|}
\hline Polymer & $\begin{array}{c}\text { Molecular } \\
\text { Formula }\end{array}$ & $\begin{array}{c}\text { Number of } \\
\text { Monomers }\end{array}$ & \left. Box Size ${\left(\AA^{3}\right.}^{\mathbf{3}}\right)$ \\
\hline PEEK & $\mathrm{C}_{19} \mathrm{H}_{14} \mathrm{O}_{3}$ & 39 & $28.6 \times 28.6 \times 28.6$ \\
\hline PBM & $\mathrm{C}_{20} \mathrm{H}_{14} \mathrm{~N}_{4}$ & 37 & $28.8 \times 28.8 \times 28.8$ \\
\hline Kapton & $\mathrm{C}_{22} \mathrm{H}_{12} \mathrm{O}_{5} \mathrm{~N}_{2}$ & 34 & $30.0 \times 30.0 \times 30.0$ \\
\hline PEI & $\mathrm{C}_{37} \mathrm{H}_{26} \mathrm{O}_{6} \mathrm{~N}_{2}$ & 20 & $29.1 \times 29.1 \times 29.1$ \\
\hline PC & $\mathrm{C}_{16} \mathrm{H}_{16} \mathrm{O}_{3}$ & 40 & $27.7 \times 27.7 \times 27.7$ \\
\hline
\end{tabular}

